\title{
Anxiety Levels and Needs of Fathers of Children Hospitalized in Pediatric Surgery Intensive Care Units
}

\author{
(1) Nurdan Akçay Didişen1, (1) Atiye Karakul2, (1) Sevinç Ertürk³, (1) Zafer Dökümcü4 \\ ${ }^{1}$ Ege University Faculty of Nursing, Department of Pediatric Nursing, İzmir, Turkey \\ ${ }^{2}$ Katip Çelebi University Facult of Medicine, Department of Pediatric Nursing, Izmir, Turkey \\ ${ }^{3}$ Pediatric Surgery Intensive Care Unit, İzmir, Turkey \\ ${ }^{4}$ Ege University Faculty of Medicine, Department of Pediatric Surgery, İzmir, Turkey
}

\begin{abstract}
Aim: The purpose of this study was to determine the anxiety levels and needs of those fathers whose children were hospitalized in a pediatric surgery intensive care unit.

Materials and Methods: This cross-sectional study was conducted with the fathers of children hospitalized in a pediatric surgery intensive care unit in 2016/2017 by using the critical care family needs inventory (CCFNI), and State and Trait Anxiety scale. Setting: Turkey, a university hospital.

Results: This study included 113 fathers. The fathers' mean age was $36.6 \pm 6.31$ years. There was a weak positive correlation between the scores the fathers obtained from the State Anxiety scale and the CCFNI. There was a difference between the fathers' intensive care needs in terms of their education levels. While "feeling that hospital personnel are attentive to the patient" was important for $92 \%$ of the fathers, "being sure that as much care as possible is given" was important for $88.5 \%$ and "being informed about the patient at least once a day" was important for $85.8 \%$.

Conclusion: The anxieties and needs of the fathers of the patients staying in a pediatric surgery intensive care unit were high, particularly in those with a low educational level. Health professionals should be aware of the fathers' feelings, needs and stressors so that they can provide interventions specific to fathers.
\end{abstract}

Keywords: Anxiety, father, needs, pediatric surgery, intensive care

\section{Introduction}

A child's admission to a surgical clinic or intensive care unit has many effects on their parents (1). Many stressors arising due to intensive care affect not only family functions but also the physiological and psychosocial well-being of families (2-4). The activities of daily living of families whose children stay in intensive care units are disrupted and families have difficulty in fulfilling their responsibilities (5).
This study provides an understanding of the anxiety levels and needs of the fathers.

\section{Background}

Stress may result from such situations as fear of the unknown, fear of death, fear of not waking up after anesthesia, loss of control, pain, isolation, separation from loved ones or being deprived of social life. In addition to these, many other factors such as the strangeness of

\section{Address for Correspondence}

Nurdan Akçay Didişen Assistant Professor, PhD, RN, Ege University Faculty of Nursing, Department of Pediatric Nursing, izmir, Turkey Phone:+90 2323115561 E-mail: nakcayyy@gmail.com / nurdan.akcay@ege.edu.tr ORCID: orcid.org/0000-0002-4371-6020 Received: 06.04.2019 Accepted: 31.05.2019

${ }^{\circ}$ Copyright 2020 by Ege University Faculty of Medicine, Department of Pediatrics and Ege Children's Foundation The Journal of Pediatric Research, published by Galenos Publishing House. 
the hospital setting, health care team's use of unfamiliar medical terms, the use of unfamiliar devices (e.g. monitors, ventilators, infusion pumps) or alarm sounds and lights from these devices are indicated to affect individuals' anxiety levels (6-9). The leading causes of stress and anxiety in these families are the history of the disease, fear of losing a loved one, issues resulting from moving to a new place, financial concerns, role changes and separation from other family members (10). Mild anxiety can increase spontaneous attention, courage and assertiveness. An individual's ability to perceive, comprehend and make decisions decreases as the level of anxiety increases. Parents' suffering intense anxiety can be prevented from understanding the information given about the child appropriately, interpreting the events realistically, making appropriate decisions, participating in the child's care or remembering the proper coping methods they had utilized previously (11). In the literature, it has been reported that parents whose children stay in surgical clinics experience various emotional conditions such as stress and anxiety $(12,13)$. Parents of a child who is admitted to a surgical intensive care unit experience a crisis due to the child's sudden illness or planned major surgical intervention (5).

Parents of children admitted to an intensive care unit want to stay with their children constantly, to take part in the child's care, to receive accurate information about the child's disease and the prognosis of the disease, to be informed about any change in the child's condition, to be helped and supported by health professionals, and to be in constant contact with health professionals $(6,14,15)$. Parents also want to be sure that the members of the healthcare team regard their child as an individual and try to treat their child in the best way $(3,9,14,16,17)$.

\section{Aim}

The aim of this study was to determine the anxiety levels and needs of those fathers whose children were hospitalized in a pediatric surgery intensive care unit.

\section{Materials and Methods}

This cross-sectional study was conducted with fathers who had children hospitalized in the pediatric surgery intensive care unit of a university hospital for at least 48 hours between November 1, 2015 and March 1, 2017 and who also agreed to participate in the study. During this period, 237 patients were admitted to the pediatric surgery intensive care unit. The power analysis was used to calculate the sample size for finite population and it was decided to include 147 fathers at a 95\% confidence interval with a margin of error of 0.05 . Of the 147 fathers included in the study, 24 were excluded because they filled in the questionnaires incompletely or incorrectly. Thus, 113 fathers comprised the study sample.

\section{Measuring Instruments}

In this study, the sociodemographic characteristics questionnaire, state and trait anxiety inventory, CCFNI and child information form were used.

\section{Sociodemographic Characteristics Questionnaire}

This questionnaire including 12 items questioning the fathers' sociodemographic characteristics was developed by the researcher in line with the relevant literature $(1,3,6,8,9,13,16,18-20)$.

\section{State and Trait Anxiety Inventory (Self-report form) STAI form TX-1,2}

The STAI developed by Spielberger et al., and adapted to Turkish by Öner and LeCompte (21) (1985) includes 40 items. Of these items, 20 assess state anxiety and the other 20 assess trait anxiety. Responses to each item in the state anxiety inventory have 4 options: 1) not at all, 2) somewhat, 3) much, and 4) completely.

\section{Critical Care Family Needs Inventory}

In 1991, Leske evaluated the construct validity of this scale through factor analysis and reported that its Cronbach's alpha reliability coefficient was 0.9 . The scale consists of 4 subscales including 44 items questioning the needs of the family members (22). The results of İseri's study revealed that the reliability and validity of the scale was high for Turkey (8). To use the scale in the present study, written permission was obtained from its author.

\section{Child Information Form}

This form was developed by the researcher to collect data about children staying in the intensive care unit. The form includes items questioning the child's age, gender, nutrition style, respiratory support, and length of stay in the intensive care unit. The form was filled in by the researcher.

\section{Procedure}

In the data collection process of the fathers, those who met the inclusion criteria and agreed to participate in the study were informed about the purpose and method of the study using a face-to-face interview technique, and their written informed consent was obtained.

After the fathers were informed, the sociodemographic characteristics questionnaire, developed by the researcher 
in line with the relevant literature, was used to collect data on their socio-demographic characteristics such as place of residence, educational status, social security status, monthly income status, history of previous hospitalizations, the CCFNI was used to determine the needs of the participating fathers, the STAI form was used to determine the fathers' anxiety levels, and the child information form was used to collect data.

\section{Ethics}

This study was approved by the Ege University Nursing Faculty Scientific Ethics Committee of the University (approval number: 2015-110) and the clinic where the study was to be conducted. After the fathers included in the research were informed about the purpose of the study, their written consent indicating that they agreed to participate in the study was obtained.

\section{Statistical Analysis}

The SPSS for Windows 22.0 package program was used for the statistical analysis of the study data. The sociodemographic characteristics of the fathers included in the study were assessed in numbers and percentages. Whether the data was normally distributed or not was determined with the Kolmogorov-Smirnov test. As the data was normally distributed, Mann-Whitney $U$ test and Kruskal-Wallis test were used to analyze the data. To examine the relationship between the scales, the Pearson correlation analysis was performed. The results were considered statistically significant at the $p<0.05$ level (95\% confidence interval).

\section{Results}

The mean age of the participating fathers was 36.6 \pm 6.31 ( $\min =22, \max =57$ ) years. While $58.4 \%$ of the fathers had spent $2 / 3$ of their lives in a city, $24.8 \%$ spent it in a district/ town and $16.8 \%$ in a village. While their children were in the intensive care unit, $40.7 \%$ of the fathers stayed in the hospital, $38.1 \%$ in their own home, $15.9 \%$ in a relative's home, $3.5 \%$ in a hotel and $1.8 \%$ in a friend's home. Of the fathers, $66.4 \%$ had a nuclear family, $26.5 \%$ had an extended family, $4.4 \%$ had a traditional family, $2.7 \%$ had a fragmented family. In terms of family size, $34.5 \%$ had one child, 39.2\% had two children, $20.4 \%$ had three children. In terms of educational status, $39.8 \%$ were primary school graduates, $24.8 \%$ were high school graduates and $29.2 \%$ had a higher education. In terms of financial security, $91.2 \%$ had social security and $61.9 \%$ had an income equal to expenses. Additionally, $56.6 \%$ did not have a previous hospitalization experience and $47.8 \%$ had no chaperone experience previously (Table 1).

According to the socio-demographic characteristics of the children of the fathers included in the study sample, the children's mean age was $5.37 \pm 4.67$ ( $\min =1, \max =17$ )

Table I. Sociodemographic characteristics of fathers

\begin{tabular}{|c|c|c|}
\hline & Number (n) & Percentage (\%) \\
\hline \multicolumn{3}{|c|}{ Place of residence } \\
\hline City & 66 & 58.4 \\
\hline District/town & 28 & 24.8 \\
\hline Village & 19 & 16.8 \\
\hline
\end{tabular}

Place stayed in during child's hospitalization

\begin{tabular}{|l|l|l|}
\hline Hotel & 4 & 3.5 \\
\hline A relative's home & 18 & 15.9 \\
\hline A friend's home & 2 & 1.8 \\
\hline Hospital & 46 & 40.7 \\
\hline His/her own home & 43 & 38.1 \\
\hline
\end{tabular}

Family type

\begin{tabular}{|l|l|l|}
\hline Nuclear & 75 & 66.4 \\
\hline Extended & 30 & 26.5 \\
\hline Traditional & 5 & 4.4 \\
\hline Fragmented & 3 & 2.7 \\
\hline
\end{tabular}

Education

\begin{tabular}{|l|l|l|}
\hline Illiterate/low literacy & 7 & 6.2 \\
\hline Elementary/secondary school & 45 & 39.8 \\
\hline High school & 28 & 24.8 \\
\hline University or higher & 33 & 29.2 \\
\hline Social security & 103 & 91.2 \\
\hline Yes & 10 & 8.8 \\
\hline No & \multicolumn{2}{|l}{} \\
\hline
\end{tabular}

Income status

\begin{tabular}{|l|l|l|}
\hline Income less than expenses & 27 & 23.9 \\
\hline Income equal to expenses & 70 & 61.9 \\
\hline Income higher than expenses & 16 & 14.2 \\
\hline
\end{tabular}

History of previous hospitalizations

\begin{tabular}{|l|l|l|}
\hline Yes & 49 & 43.4 \\
\hline No & 64 & 56.6 \\
\hline \multicolumn{2}{|l|}{ History of being chaperone previously } \\
\hline Yes & 59 & 52.2 \\
\hline No & 54 & 47.8 \\
\hline Total & 101 & 100.0 \\
\hline
\end{tabular}


years. Of the children, 34\% were girls, $58.5 \%$ had parenteral nutrition, $13.2 \%$ had oral and parenteral nutrition, $11.3 \%$ had oral and enteral nutrition, $9.4 \%$ had parenteral and enteral nutrition, $65.4 \%$ did not receive oxygen support, and $3.8 \%$ were intubated.

The mean score obtained from the CCFNI by the participating fathers was $147.61 \pm 1.55$ ( $\min =02$, $\max =05$ ). The mean scores obtained from the subscales of the CCFNI were $46.11 \pm 0.68(\min =25, \max =60)$ for the Support and Proximity Need subscale, $36.14 \pm 0.31$ ( $\min =27, \max =40$ ) for the Information Need subscale, 24.33 \pm 0.44 ( $\min =13$, $\max =32)$ for the Comfort Need subscale, and 33.68 \pm 0.21 ( $\min =27, \max =36)$ for the Assurance Need subscale (Table 2).

The items responded to as "very important" by the participating fathers were as follows: to feel that hospital personnel care about the patient (92.5\%), to be assured that the best possible care is being given (88.5\%), to receive information about the patient at least once a day (85.8\%), to have questions answered honestly (84.1\%), to feel there is hope $(84.1 \%)$, to know the facts about the patient's progress $(83 \%)$, to receive understandable explanations $(80.5 \%)$, to know the reasons for the interventions the patient undergoes (78.8\%), to know exactly what is being done for the patient (77\%), to talk to the doctor every day (77\%), to be called at home about changes in the patient's condition (76.1\%), to know the expected outcome (76.1\%), to know how the patient is being treated medically (74.3\%), to have directions about what to do when they are at the bedside (72.6\%), and to be informed about the environment in the critical care unit before going there (70.8\%).

The items responded to as "not important" by the participating fathers were as follows: to have another person with you when visiting the critical care unit (32.7\%), to be visited by a hodja (25.7\%), to have a bathroom near

\begin{tabular}{|c|c|c|c|c|}
\hline CCFNI Subscales & $\begin{array}{l}\text { The number } \\
\text { of the items }\end{array}$ & $x$ & SS & $\begin{array}{l}\text { Cronbach's } \\
\text { alfa } \\
\text { coefficient }\end{array}$ \\
\hline $\begin{array}{l}\text { Support and } \\
\text { proximity need }\end{array}$ & 15 & 46.11 & 0.68 & 0.836 \\
\hline Information need & 12 & 36.14 & 0.31 & 0.782 \\
\hline Comfort need & 8 & 24.33 & 0.44 & 0.812 \\
\hline Assurance need & 9 & 33.68 & 0.21 & 0.702 \\
\hline CCFNI total & 44 & 147.61 & 1.55 & 0.921 \\
\hline
\end{tabular}

the waiting room (17.7\%), to know which staff members could give what information (17.7\%), to be informed about religious services $(16.8 \%)$, to have a telephone near the waiting room (15\%), to change visiting hours in case special conditions arise (14.2\%), to be alone whenever you want to $(10 \%)$ and to have someone to help with family problems (10.6\%).

While the mean trait anxiety score obtained by the fathers was $46.76 \pm 0.60$ ( $\min =31, \max =67)$, the mean state anxiety score was $41.93 \pm 0.59$ ( $\min =28, \max =66$ ) (Figure 1).

The comparison of the fathers' socio-demographic characteristics with the scores they obtained from the CCFNI and its subscales are shown in table 3. There was a statistically significant relationship between the education variable and the fathers' overall CCFNI scores and Comfort Need subscale scores $(p<0.05)$. As the fathers' education levels increased, so did their critical care needs. There was a difference between the fathers with higher education and the illiterate and primary school graduate fathers, and between high school graduate fathers and illiterate fathers $(p<0.05)$. There was a statistically significant relationship between the education variable and the fathers' Support and Proximity Need subscale scores $(p=0.029)$ (Table 3). As the fathers' education levels increased, so did their support and proximity needs.

There was a statistically significant relationship between the education variable and the fathers' trait anxiety scores $(p=0.04)$. There was a difference between those fathers with higher education and those who only received primary school education $(p<0.05)$ (Table 3$)$.

\section{Discussion}

Parents whose children are admitted to the critical care unit are faced with many stressors. Among these stressors, the deterioration of family integrity is the leading one.

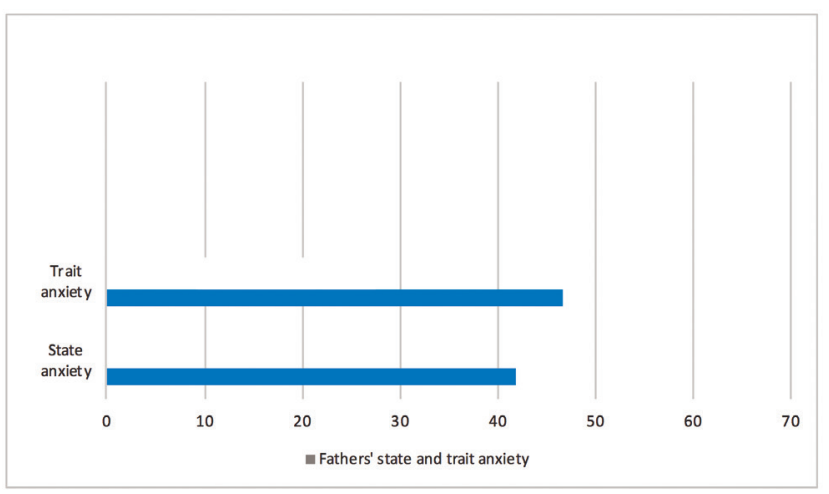

Figure 1. Mean scores fathers obtained from the State and Trait Anxiety scale 
Akçay Didişen et al.

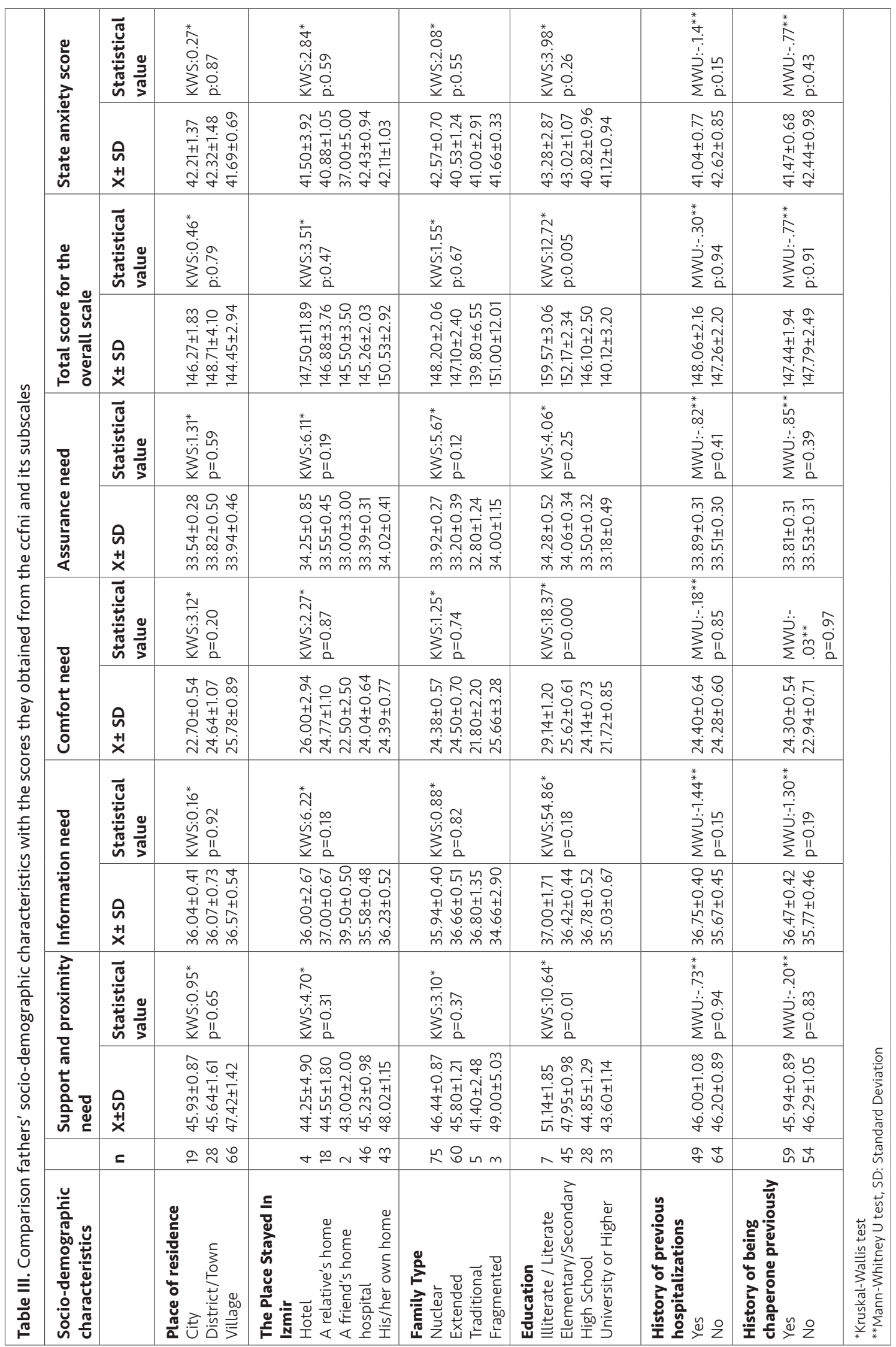


Coping with the problems arising from the child's admission to an intensive care unit and dealing with the child/family holistically are very important if quality patient care is to be achieved. In meeting the patients' and their parents' needs, primary responsibility lies with health professionals. In this study, conducted to determine the fathers' critical care needs and anxiety status, the vast majority of the fathers stated that their needs were very important or important.

In studies conducted by Stremler et al. (15), anxiety levels of parents with children receiving intensive care were high. In the study conducted by Board (2004), fathers were reported to suffer high levels of anxiety due to the intensive care setting, children's appearance and behavior, and intensive care procedures (23). In Dudley and Carr's study (2004), families were determined to experience feelings of anxiety, shock and uncertainty about their children (18). Chui and Chan (2007) interviewed parents whose children were in the intensive care unit and found that parents' anxiety levels were quite high (6). In the current study, the fathers' status and trait anxiety levels were high. To reduce parents' anxiety levels, environmental arrangements can be made. Currently, in Turkey, parents cannot stay with their children in the intensive care unit. However, in North America, parents can stay with their children (24). In the literature, it has been reported that parents' staying with their child in the intensive care environment reduces their anxiety level $(18,19,25)$. In a study by Colville et al. (26) (2009), parents reported that their anxiety regarding their child's condition was greater than their anxiety regarding their child's condition when they were healthy. The parents also stated that their stress increased when they could not communicate with anybody about their child's progress. In Majdalani et al. (27) study (2014), families stated that they needed to be informed about the condition of their child to reduce their anxiety. Thus, it is very important for families to be regularly informed by health personnel.

There was no significant relationship between the parents' anxiety levels and their critical care needs. The fathers' anxiety levels were high, and their needs were a lot. It is important that caregivers are aware of the needs of the fathers. It is also necessary to consider that the father may be anxious. Initiatives to reduce the anxiety of parents and meet their needs should be planned. Fathers participating in this study rated the item 'the need for information' as very important. This result is similar to previous studies, which identified the importance of information $(9,21,28)$. McKiernan and McCarthy stated that daily information given to family members increased the satisfaction of these family members (28).
In Uzun et al. (10) study (2002), the first three needs indicated by family members were "to be assured the best possible care is being given". In Tokur et al. (20) study (2016), while $90 \%$ of the patients' relatives wanted to see their patients every day, $96 \%$ wanted to be informed about their patient's condition every day. In the present study, the fathers considered the following items very important: "to feel that hospital personnel care about the patient", "to be assured that the best possible care is being given", "to receive information about the patient at least once a day", "to have questions answered honestly", "to feel there is hope", and "to know the facts about the patient's progress".

As the fathers' education levels increased, so did their critical and support/proximity needs. In a study performed by İşeri (2010), no correlation was determined between the participants' educational status and their assurance, support and proximity, information and comfort needs (8). In their study, Medonca and Warren (17) determined that the illiterate participants had a higher expectation of support.

In Maxwell's study (2010), families obtained the highest mean scores from the assurance, proximity, information, comfort and support need subscales respectively (9). In Majdalani et al. (27) study, the families described their experience relating to the intensive care setting, their child's prognosis and expectations of health professionals as a journey into the unknown. Board (2004) reported that the father's communication with health professionals was poor and that they did not know how to help their children (23). In a study conducted by Berube et al. (29) (2014), they concluded that the parents whose children were in the intensive care unit felt exhausted, wanted to feel that they were supported by others and wanted to be informed of their child's condition. Also the families' support and proximity needs were high.

In a study conducted by Carlson et al. (30), of the parents whose children were in intensive care units, 20\% were satisfied with their communication with physicians and nurses, being informed about their children's condition, and receiving emotional support. Uzun et al. (10) reported (2002) that many of the patients' families regarded their need to be informed about the patient's condition and to receive psychological support as more important than their personal/physical needs. Clinical protocols should be developed to meet the needs of the father in line with these requirements.

\section{Limitation of the Study}

Our study had several limitations. The first one is that the study was performed only in the surgical intensive care 
unit in one center. In addition, the majority of the participating fathers' economic status, social security and education levels were good. Therefore, the results of study cannot be generalized to other centers as priorities may change.

\section{Conclusion}

In conclusion, the anxiety levels and needs of those fathers whose children were admitted to the pediatric intensive care unit were high. The fathers wanted to know that their child received the best possible care from the hospital staff, and to receive clear, understandable and accurate information about their child. In order to improve the conditions and the quality of care in the existing pediatric surgery intensive care units in Turkey, hospital and/or clinical protocols should be developed to meet the needs of the fathers and to establish effective communication with them.

\section{Ethics}

Ethics Committee Approval: This study was approved by the Ege University Nursing Faculty Scientific Ethics Committee of the University (approval number: 2015-110) and the clinic where the study was to be conducted.

Informed Consent: A consent form was filled out by all participants.

Peer-review: Externally peer-reviewed.

\section{Authorship Contributions}

Surgical and Medical Practices: S.E., Z.D., Concept: N.A.D., A.K., S.E., Z.D., Design: .A.D., A.K., S.E., Z.D., Data Collection or Processing: S.E., Analysis or Interpretation: A.K., Literature Search: N.A.D., A.K., S.E., Z.D., Writing: N.A.D., A.K.

Conflict of Interest: No conflict of interest was declared by the authors.

Financial Disclosure: The authors declared that this study received no financial support.

\section{References}

1. Grandjean C, Latour IM, Cotting I, Fazan MC, Leteurtre S, Ramelet AS. Measurement of parent satisfaction in the paediatric intensive care unit-Translation, cultural adaptation and psychometric equivalence for the French-speaking version of the EMPATHIC-65 questionnaire. Intensive Crit Care Nurs 2017;38:40-5.

2. Chien WT, Chiu YL, Lam LW, Ip WY. Effects of a needs-based education programme for family carers with a relative in an intensive care unit: A quasi-experimental study. Int I Nurs Stud 2006;43:39-50.

3. Shudy M, de Almeida ML, Ly S, et al. Impact of pediatric critical illness and injury on families: a systematic literature review. Pediatrics 2006;118 Suppl 3:S203-18.
4. Wasserfallen JB, Bossuat C, Perrin E, Cotting J. Cost borne by families of children hospitalised in a paediatric intensive care unit: A pilot study. Swiss Med Wkly 2006;136:800-4.

5. Young Seideman R, Watson MA, Corff KE, Odle P, Haase I, Bowerman IL. Parent stress and coping in NICU and PICU. I Pediatr Nurs 1997;12:169-77.

6. Chui WY, Chan SW. Stress and coping of Hong Kong Chinese family members during a critical illness. I Clin Nurs 2007;16:37281.

7. Hollywood M, Hollywood E. The lived experiences of fathers of a premature baby on a neonatal intensive care unit. I Neonatal Nurs 2011;17:32-40.

8. İşeri Ö. Family members' and nurses' perceptions of the needs of intensive care unit patient relatives. Cumhuriyet University Health Sciences Institute 2010.

9. Maxwell KE, Stuenkel D, Saylor C. Needs of family members of critically ill patients: A comparison of nurse and family perceptions. Heart Lung 2007;36:367-76.

10. Uzun Ö, Özer N, Akyıl RÇ. Needs of patients' families in some surgical clinics and surgical intensive care units. Eurasian / Med 2002;34:39-45.

11. Akşit $\mathrm{S}$, Cimete $\mathrm{G}$. The effect of nursing interventions on the anxiety level of mothers after admission of their children to the intensive care unit. Cumhuriyet Nursing Journal 2001;5:25-36.

12. Leung K, Chien WT, Mackenzie AE. Needs of Chinese Families of Critically Ill Patients. West I Nurs Res 2000;22:826-40.

13. Söderström IM, Saveman BI, Benzein E. Interactions between family members and staff in intensive care units - an observation and interview study. Int I Nurs Stud 2005;23:2-30.

14. Meyer EC, Snelling LK, Myren-Manbeck LK. Pediatric intensive care: The parents' experience. AACN Clin Issues 1998;9:64-74.

15. Stremler R, Haddad S, Pullenayegum E, Parshuram C. Psychological Outcomes in Parents of Critically Ill Hospitalized Children. J Pediatr Nurs 2017;34:36-43.

16. Çalışır $H$, Şeker $S$, Güler $F$, Anaç GT, Türkmen M. The anxiety levels and needs of infants' parents in a neonatal intensive care unit. Cumhuriyet Nursing Journal 2008;12:31-44.

17. Mendonca D, Warren Nancy A. perceived and Unmet Needs of Critical Care Family Members. Crit Care Nurse 1998;21:58-67.

18. Dudley SK, Carr JM. Vigilance: The experience of parents staying at the bedside of hospitalized children. I Pediatr Nurs 2004;19:267-75

19. Matthews EE, Neu M, Cook PF, King N. Sleep in mother and child dyads during treatment for pediatric acute lymphoblastic leukemia. Oncol Nurs Forum 2014;41:599-610.

20. Tokur ME, Aydın K, Çalışkan T, Savran Y, Cömert B, Ergan B. Perception of and satisfaction from Intensive Care in Patients' Relatives. Yoğun Bakım Derg 2016;7:57-61.

21. Öner L, Le-Compte A. Durumluk-sürekli kaygı envanteri el kitabı (2. Baskı). İstanbul Boğaziçi Üniversitesi Yayınları;1985.

22. Molter NC. Needs of the relatives of critically ill patients: A descriptive study. Heart Lung 1979;8:332-9.

23. Board R. Father stress during a child's critical care hospitalization. Journal of Pediatric Health Care 2004;18:244-9. 
24. Stremler R, Wong L, Parshuram C. Practices and provisions for parents sleeping overnight with a hospitalized child. J Pediatr Psychol 2008;33:292-7.

25. Smith AB, Hefley GC, Anand KIS. Parent bed spaces in the PICU: Effect on parental stress. Pediatr Nurs. 2007;33:215-21.

26. Colville G, Darkins J, Hesketh J, Bennet V, Alcock J, Noyes J. The impact on parents of a child's admission to intensive care: Integration of qualitative findings from a cross-sectional study. Intensive Crit Care Nurs 2009;25:72-9.

27. Majdalani MN, Doumit MAA, Rahi AC. The lived experience of parents of children admitted to the pediatric intensive care unit in Lebanon. Int J Nurs Stud 2014;51:217-25.
28. McKiernan M, McCarthy G. Family members' lived experience in the intensive care unit: a phemenological study. Intensive Crit Care Nurs 2010;26:254-61.

29. Berube KM, Fothergill-Bourbonnais F, Thomas M, Moreau D. Parents' Experience of the Transition with their Child from a Pediatric Intensive Care Unit (PICU) to the Hospital Ward: Searching for Comfort Across Transitions. I Pediatr Nurs 2014;29:586-95.

30. Carlson EB, Spain DA, Muhtadie L, McDade-Montez L, Macia KS. Care and caring in the intensive care unit: Family members' distress and perceptions about staff skills, communication, and emotional support. / Crit Care 2015;30:557-61. 